\title{
Nomograms for Predicting Overall Survival Among Patients with Craniopharyngiomas at Initial Diagnosis: A SEER Population-Based Analysis
}

\author{
Haibo Teng ${ }^{1, *}$ \\ Zhiyong Liu' ${ }^{1} *$ \\ Ouying Yan $^{2}$ \\ Wenbo $\mathrm{He}^{1}$ \\ Danyang Jie ${ }^{3}$ \\ Yuanwei Qie ${ }^{4}$ \\ Jianguo $\mathrm{Xu}^{\prime}$
}

'Department of Neurosurgery, West China Hospital, Sichuan University, Chengdu, People's Republic of China;

${ }^{2}$ The Affiliated Cancer Hospital of Xiangya School of Medicine, Central South University, Changsha, Hunan, People's Republic of China; ${ }^{3}$ West China School of Medicine, West China Hospital, Sichuan University, Chengdu, People's Republic of China; ${ }^{4}$ Health Management Center of West-China Fourth Hospital, Sichuan University, Chengdu, People's Republic of China

*These authors contributed equally to this work

\begin{abstract}
Background: Craniopharyngiomas $(\mathrm{CPs})$ are relatively rare benign tumor located in the central nervous system (CNS). This study investigates the related risk factors of survival of craniopharyngiomas and develops a simple but detailed method predicting prognosis based on the Surveillance, Epidemiology, and End Results (SEER) database in order to improve the clinic management of CPs.
\end{abstract}

Methods: Between 2004 and 2017, 1213 patients diagnosed with craniopharyngiomas registered at the program and were included in the SEER-21 registry database. Overall survival (OS) curves were plotted with the Kaplan-Meier method and significance was determined by Log rank test. Single- and multiple-factor regression analyses were made using Cox proportional hazards model to identify independent predictors related to OS. Subsequently, we developed a nomogram with those factors to predict 3-, 5- and 10-year OS of craniopharyngiomas patients.

Results: We identified 1213 patients with craniopharyngioma. The OS rates at 3, 5, and 10 years after diagnosis were $89.1 \%, 86.2 \%$, and $83 \%$. Age, ethnicity, tumor size and radiation therapy were confirmed to be predictors correlating with OS at initial diagnosis. In multivariate analysis, we found that younger age $(\mathrm{P}<0.001)$, smaller tumor size $(\mathrm{P}<0.001)$, white ethnicity $(\mathrm{P}<0.001)$ and radiation therapy $(\mathrm{P}=0.004)$ were the factors that remained significantly associated with better survival. A nomogram was successfully constructed and validated by ROC, calibration plots and C-index of 0.773 (95\% CI, 0.708-0.838).

Conclusion: The well-calibrated nomogram is the first clinical prediction model for predicting the prognosis for patients with craniopharyngiomas at initial diagnosis. Our study indicates that the surgical effect is not clear. Younger white patients with radiotherapy have a better prognosis, and the gross total resection (GTR) was not effective in prolonging the OS of a patient compared to no surgery and subtotal resection (STR).

Keywords: craniopharyngioma, nomogram, overall survival, SEER

\section{Introduction}

Craniopharyngiomas are relatively rare benign tumor located in the central nervous system that only constitute $1.2-4.6 \%$ of all intracranial tumors. However, they are the most common intracranial nonglial tumor in children. ${ }^{1,2}$ Increased intracranial pressure is a common manifestation of CPs. Visual acuity disorder and endocrine deficiencies are also the early symptoms. ${ }^{3}$ The craniopharyngiomas has a bad midand long-term prognosis of 54-96\% overall survival (OS) at 5 years, $40-66 \%$ at 10 years, and $66-85 \%$ at 20 years. $^{4,5}$ In addition, craniopharyngiomas had a high
Correspondence: Jianguo $\mathrm{Xu}$ Department of Neurosurgery, West China Hospital, Sichuan University, Chengdu, People's Republic of China Email xujg@scu.edu.cn 
propensity for recurrence, accompanying by a 3-6 times higher mortality rate than the general population. ${ }^{6}$ Treatment of craniopharyngioma still has been facing enormous challenges confronting neurosurgeons. Total removal is considered the best surgical treatment for CPs in the past time. ${ }^{7,8}$ However, current management of CPs tend to combining surgery and radiotherapy in order to limit morbidity of unacceptable hypothalamic injury. ${ }^{9,10}$ There is a lack of data on the prognostic factors associated with survival due to the low incidence of craniopharyngiomas. Several factors, including age, sex, surgical interventions, radiation therapy, histological type and tumor size have been analyzed for their important influence on survival of CPs in some previous studies, most of which were small retrospective analyses and case studies. ${ }^{2,11}$ The prognostic prediction model, however, was still needed to be constructed to accurately predict the survival of CPs. In fact, we would like to make an initial prognosis of survival at the first consultation with limited investigations and choose a relatively safe and appropriate treatment option. Further work is required with larger sample sizes to explore risk factors associated with CPs. Thus, we used the Surveillance, Epidemiology, and End Results (SEER) database to construct the first OS-related prediction model of CPs patients at initial diagnosis. For the purpose of adjusting clinical practice and improving patient survival.

\section{Methods}

\section{Study Population}

We abstracted data from SEER 21 registries research database, which is maintained by the National Cancer Institute. ${ }^{12}$ All these data are included in the SEER database and follow-up information was also collected from the database and updated to December 31, 2017.

The study protocol was approved by the Research Ethics Committee of West China Hospital. Because the information for each patient was derived from a public database, the research ethics board of West China Hospital exempted this study from review. The patient information and the SEER* Stat software were acquired from the SEER website (https://seer.cancer.gov/) after submitting the data agreement to the SEER administration.

\section{Cohort Selection}

We created a case listing of CPs by SEER*Stat version 8.3.6. The dataset was defined using International Classification of Diseases for Oncology, third Edition
(ICD-O-3) craniopharyngioma codes 9350-9352 from 2004 to 2017 ( $n=2150$ patients). Patients with diagnoses histologically confirmed craniopharyngioma were selected ( $n=1869$ patients). Patients with more than 1 tumor in this series were excluded from this analysis ( $n=50$ patients). We used the survival months flag variable to identify missing or incomplete data ( $<1$ months) on survival time ( $\mathrm{n}=53$ patients). Other exclusion criteria included patients with an unknown ethnicity ( $n=17$ patients), unknown size $(\mathrm{n}=544$ patients $)$ and unknown surgery status $(\mathrm{n}=4$ patients). The final datasets had a total of 1213 patients (Figure 1).

\section{Covariates Included}

Surgical treatment was categorized into four groups according to the guidelines of SEER: observation, biopsy, STR, GTR, the results were modified as follows: C71.071.9 and C72.0-72.9: No/Biopsy $(00,20)$; STR $(21,40)$; GTR (30,55); C75.1-C75.3: No/Biopsy (00,27); STR (10-14,30,50); GTR (20-26,40,60). The following predictive factors of OS were considered: age at diagnosis (age were categorized into following five groups: $<20,20-39$, 40-59, 60-79, and >80), sex, ethnicity (white, black and other), surgery status [no surgery (including observation and local excision/biopsy), subtotal resection (STR), gross total resection (GTR)], radiation (treated versus untreated groups).

\section{Statically Analyses}

The baseline characteristics of the included cohort were summarized using descriptive statistics: age at diagnosis, sex, ethnicity, surgery status, radiation, tumor size. Overall survival (OS) was specified as time from initiation of diagnosis until death from any cause or last follow-up timepoint if the patient was alive. Survival curves with different variables were compared and visualized using Kaplan-Meier and Log rank tests. Univariate analysis of variable covariates, such as age at diagnosis, sex, ethnicity, histology, surgery status, radiation, tumor size, was performed to identify potential predictors. OS-related predictive factors were outcome by univariate and multivariate analysis according to the Cox proportional hazard model. All analyses were conducted using SPSS version 23 (IBM, Armonk, New York, USA) and P value $<0.05$ indicated statistically significant.

The results of multivariate analysis were summarized to establish the nomogram using the "survival" and "rms" packages in $\mathrm{R}$ 3.6.3. Bootstrap method was applied for 


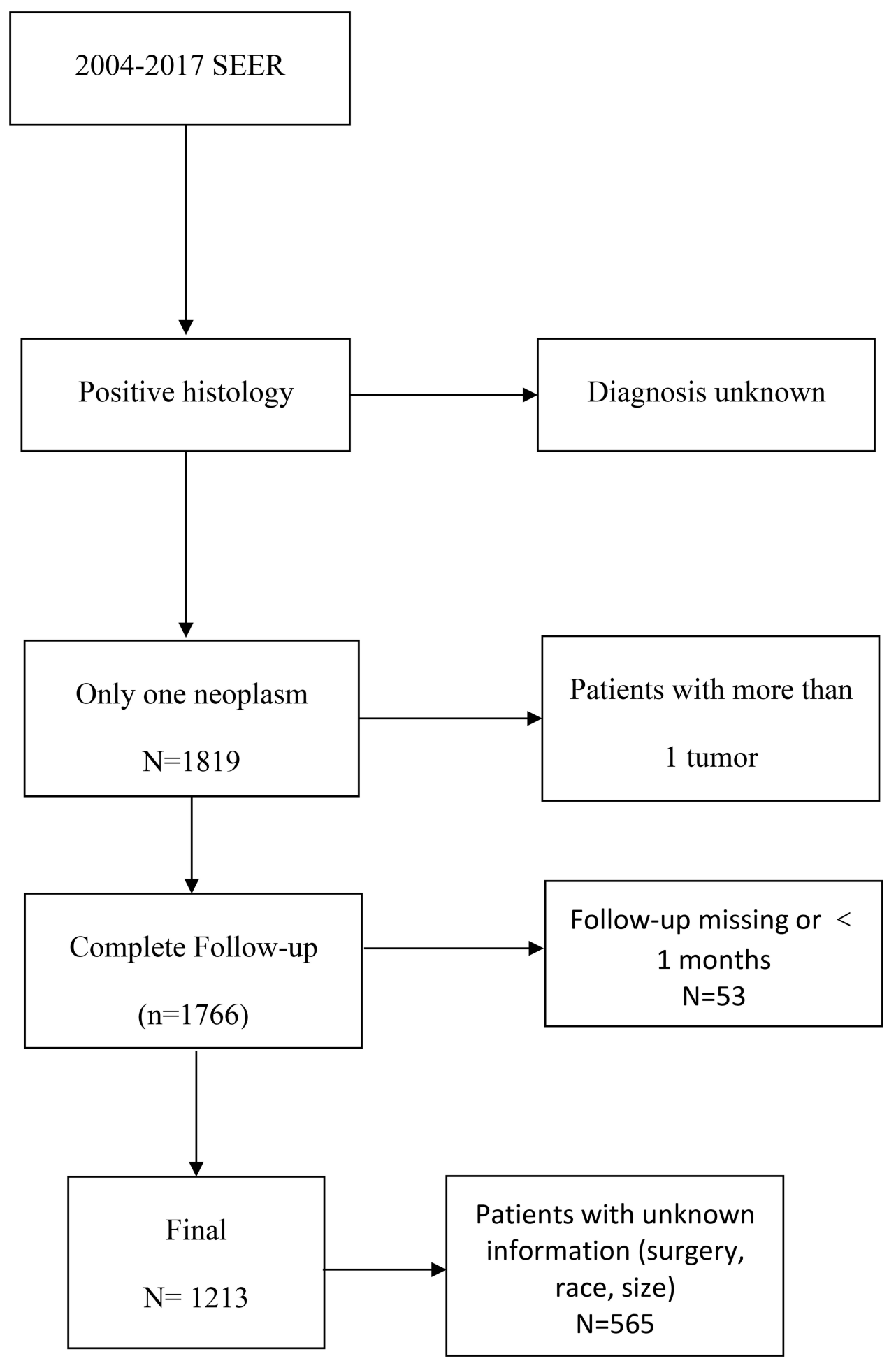

Figure I The flow chart of data process.

verification of the model. We performed 1000 resampling which contained different types and unknown types of patients and the Harrells concordance index (C-Index) were calculated to assess the predictive accuracy of nomogram. The value of c-index ranges from 0.5 to 1 .
Calibration plots were constructed to compare the predicted survival with the observed survival based on bootstrap resampling validation to verify the prediction model. In addition, the ROC curves were plotted and the areas under ROC (AUC) were computed. 


\section{Results}

\section{Description Statistics}

The demographic and clinical characteristics of the research population are summarized in Table 1. Gender of male and female showed an almost equal percentage distribution (51.4\% and $48.5 \%$, respectively), with a median age at diagnosis of 38 years (range $0-87$ years). The ethnicity of most cases was white (72.6\%), followed by black (16.1\%) and other (11.2\%). More than a third of patients, 475 (39.2\%) were adamantinomatous histology (39.2\%) and only $114(9.3 \%)$ were papillary in nature. More than half of the patients, 624 (51.4\%) were no specified histologic subtype (craniopharyngioma,

Table I Patient Characteristics in CPs Data Sets

\begin{tabular}{|c|c|}
\hline Variable & n (\%) \\
\hline \multicolumn{2}{|l|}{ Age, $y$} \\
\hline$<20$ & $398(32.8)$ \\
\hline $20-39$ & $228(18.8)$ \\
\hline $40-59$ & $382(31.5)$ \\
\hline $60-79$ & $195(16.1)$ \\
\hline$\geq 80$ & $10(0.8)$ \\
\hline \multicolumn{2}{|l|}{ Sex } \\
\hline Female & $589(48.5)$ \\
\hline Male & $624(51.4)$ \\
\hline \multicolumn{2}{|l|}{ Race/ethnicity } \\
\hline White & 881 (72.6) \\
\hline Black & $196(16.1)$ \\
\hline Other ethnicity & $136(11.2)$ \\
\hline \multicolumn{2}{|l|}{ Histology } \\
\hline Papillary craniopharyngioma & $114(9.3)$ \\
\hline Adamantinomatous craniopharyngioma & $475(39.2)$ \\
\hline Craniopharyngioma NOS & $624(51.4)$ \\
\hline \multicolumn{2}{|l|}{ Size } \\
\hline$<30 \mathrm{~mm}$ & $582(47.9)$ \\
\hline$\geq 30 \mathrm{~mm}$ & $631(52.0)$ \\
\hline \multicolumn{2}{|l|}{ Surgery } \\
\hline Observation or biospy & $263(21.7)$ \\
\hline STR & $469(38.7)$ \\
\hline GTR & $466(38.4)$ \\
\hline Surgery, NOS & $15(1.2)$ \\
\hline \multicolumn{2}{|l|}{ Radiation } \\
\hline Yes & $336(27.7)$ \\
\hline No & $877(72.2)$ \\
\hline \multicolumn{2}{|l|}{ Year of diagnosis } \\
\hline $2004-2010$ & $626(51.6)$ \\
\hline $2010-2017$ & $587(48.4)$ \\
\hline
\end{tabular}

Table 2 Treatment Modalities

\begin{tabular}{|l|c|c|}
\hline \multirow{2}{*}{ Surgery } & \multicolumn{2}{|c|}{ Radiotion } \\
\cline { 2 - 3 } & Yes & No \\
\hline STR & $165(17.6)$ & $307(32.8)$ \\
GTR & $89(35.1)$ & $374(40.0)$ \\
\hline
\end{tabular}

NOS). Concerning treatment options, $38.7 \%$ were treated by subtotal resection $(\mathrm{n}=469)$ and $27.7 \%$ radiation $(n=336)$. We further analyzed combinations of different treatments and there exist a variety of treatment options including radiotherapy (RT), STR, GTR, or any combination of these treatments (Table 2). In terms of the survival time of patients provided, with the median follow-up time of 55 months (range 1-155 months), 1003 patients were alive and 210 were deceased.

\section{Survival Statistics}

The OS rates at 3, 5, and 10 years after diagnosis were $89.1 \%, 86.2 \%$, and $83 \%$, respectively. A Kaplan-Meier curve was created to compare the OS of craniopharyngioma patients by different variable (Figure 2). The result showed that age group $(\mathrm{P}<0.001)$, ethnicity $(\mathrm{P}<0.001)$, surgery $(\mathrm{P}=0.0012)$, and radiation therapy $(\mathrm{P}<0.001)$ were significant difference. Additionally, in order to better compare different histologic subtypes, we conducted statistical analysis between ACP group and PCP group which included 589 patients. The results are displayed in Table 3. It is found that there are no statistically significant difference between different types except age $(\mathrm{P}<0.001)$ and size $(\mathrm{P}=0.009)$.

Univariate analyses of characteristics associated with the OS are presented in Table 4. Older patients $(\mathrm{P}<0.001)$, the black $(\mathrm{P}<0.001)$, craniopharyngioma NOS $(\mathrm{P}=0.049)$ and those without radiation treatment $(\mathrm{P}=0.002)$ were more likely to undergo a decreased OS. Analysis of surgical status showed that both GTR (HR, $1.110 ; 95 \%$ CI, 0.754-1.634; $\mathrm{P}=0.596)$ and STR (HR, 0.838; 95\% CI, $0.607-1.156 ; \mathrm{P}=0.282$ ) was not significantly associated with better OS when compared with no surgery group. All of the seven variables selected in the univariate analysis were entered forward into the multivariable Cox proportional hazard model and Table 4 shows the results that the older age $(\mathrm{P}<0.001)$, tumor size $\geq 30 \mathrm{~mm} \quad(\mathrm{P}<0.001)$, the black ethnicity $(\mathrm{P}<0.001)$ and treatment without radiotherapy $(\mathrm{P}=0.002)$ were considered as a probable independent predictor of decreased OS rate. 

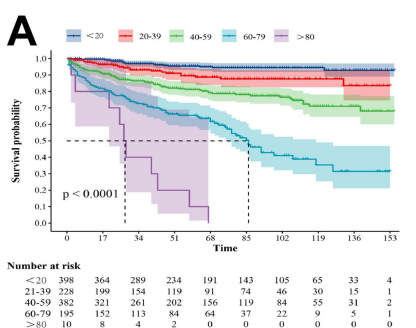

E

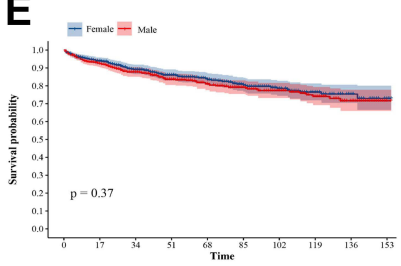

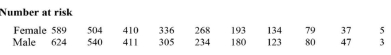
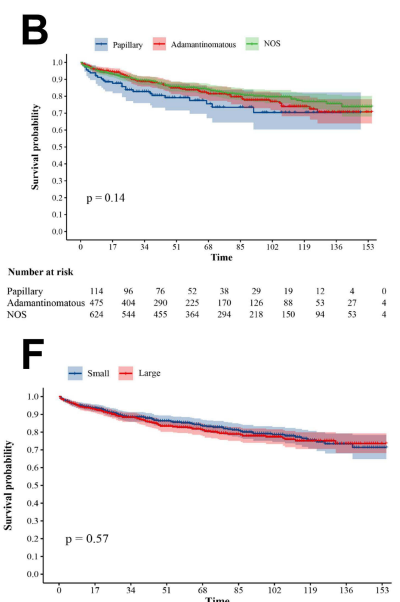

$\begin{array}{cccccccccc}\text { Number at risk } & & & & & & & & & \\ \text { Small } 582 & 504 & 404 & 324 & 263 & 204 & 138 & 83 & 47 & 3 \\ \text { Laage } 631 & 540 & 417 & 317 & 239 & 169 & 119 & 76 & 37 & 5\end{array}$
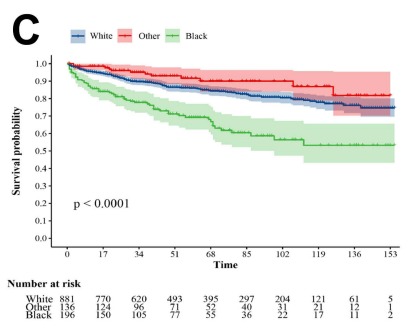

G

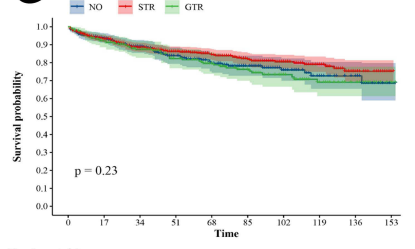

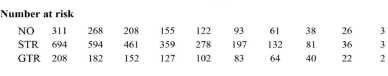
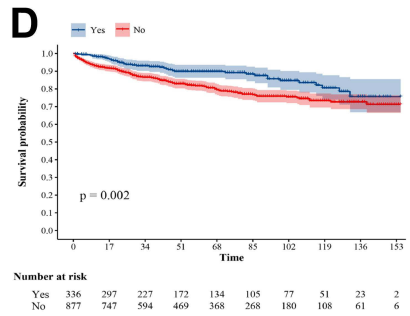

H

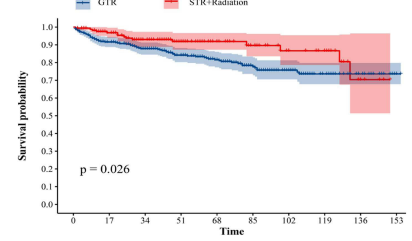

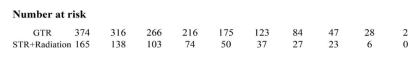

Figure 2 Kaplan-Meier curves for patients with CPs by different variates. (A) Age group, (B) histology, (C) ethnicity, (D) radiation, (E) gender, (F) tumor size, (G) surgery, (H) treatment.

\section{Prognostic Nomogram for OS}

According to the results of Cox Model, nomograms of OS (Figure 3) were generated for the predictive listed above: age, ethnicity, tumor size, and radiation therapy. The

Table 3 Univariate Analysis of Different Variables with Two Histology in 589 Patients (Measured by Pearson's X2-Test)

\begin{tabular}{|c|c|c|c|}
\hline Variable & $\begin{array}{c}\text { Adamantinomatous } \\
\qquad(n=475)\end{array}$ & $\begin{array}{l}\text { Papillary } \\
(n=\mid 14)\end{array}$ & $\mathbf{P}$ \\
\hline Age, y & & & $<0.001$ \\
\hline$<20$ & $178(37.5)$ & $3(2.6)$ & \\
\hline $20-39$ & $86(18.1)$ & $19(16.7)$ & \\
\hline $40-59$ & $145(30.5)$ & $5750.0)$ & \\
\hline 60-79 & $65(13.7)$ & $3 \mid(27.2)$ & \\
\hline$\geq 80$ & I (0.2) & $4(3.5)$ & \\
\hline Sex & & & 0.187 \\
\hline Female & $255(53.7)$ & $69(60.5)$ & \\
\hline Male & $220(46.3)$ & $45(39.5)$ & \\
\hline Race/ethnicity & & & 0.127 \\
\hline White & $350(7.4)$ & $92(80.7)$ & \\
\hline Black & $72(15.2)$ & $9(7.9)$ & \\
\hline Other ethnicity & $53(11.2)$ & $13(11.4)$ & \\
\hline Size & & & 0.009 \\
\hline$<30 \mathrm{~mm}$ & $210(44.2)$ & $66(58.0)$ & \\
\hline$\geq 30 \mathrm{~mm}$ & $265(55.8)$ & $48(42.0)$ & \\
\hline Surgery & & & 0.547 \\
\hline Observation or biospy & $183(38.5)$ & $29(25.4)$ & \\
\hline STR & $193(40.6)$ & $45(39.5)$ & \\
\hline GTR & $93(19.6)$ & $39(34.2)$ & \\
\hline Surgery, NOS & $6(1.3)$ & I (0.9) & \\
\hline Radiation & & & 0.227 \\
\hline Yes & $125(26.3)$ & $33(29.0)$ & \\
\hline No & $352(74.1)$ & $8 \mid(71.0)$ & \\
\hline
\end{tabular}

C-index of the nomogram was 0.773 (95\% CI, $0.708-$ 0.838 ), indicating that the model achieved a high predictive accuracy. Validation of the calibration curve for the probability of OS at 3-, 5- and 10-year exhibited good concordance between the predicted probability and actual probability in the dataset (Figure 4). The 3-, 5- and 10-year ROC AUC was 0.77, 0.78, 0.84, respectively (Figure 5).

\section{Discussion}

Craniopharyngioma (CP) is considered a benign, but clinically aggressive CNS neoplasm and has the possibility to recur. Operation of Craniopharyngioma is considered challenging because of serious complications and high recurrence rate, leading poor prognosis. Initial therapy, especially surgical management, still has been the subject of considerable controversy. ${ }^{13}$ Simultaneously, predicting prognosis in craniopharyngiomas has been a longstanding difficulty. Thus, better understanding the relationship between survival rates and risk factors is useful for determining an appropriate treatment strategy. In this study, 1213 cases from the SEER database, we found that age, radiation, ethnicity, tumor size were independent prognostic factors of OS. Furthermore, a nomogram was constructed to predict effectively visually the 3,5 and 10-year OS rates of patients with CPs. The model incorporated demographic, clinical characteristics with discrimination and calibration performance, which may have value in clinical applications. For a patient with craniopharyngioma diagnosed in clinic, it is possible to quickly estimate the survival of CPs according to preoperative indexes and treatment plan using the novel nomogram. 
Table 4 Univariate and Multivariate Cox Regression Analysis of Overall Survival in the Cohort

\begin{tabular}{|c|c|c|c|c|}
\hline Variable & Unvaribale Analysis & $\mathbf{p}$ & Multivarible Analysis & $\mathbf{p}$ \\
\hline & HR (95\%Cl) & & HR $(95 \% \mathrm{Cl})$ & \\
\hline Age, y & & $<0.001$ & & $<0.001$ \\
\hline$<20$ & I [reference] & & I [reference] & \\
\hline $20-39$ & $2.306(1.237-4.300)$ & & 2.509 (I.342-4.689) & 0.004 \\
\hline $40-59$ & $4.88 I(2.92 I-8.153)$ & & $5.575(3.316-9.372)$ & $<0.001$ \\
\hline $60-79$ & $12.227(7.337-20.376)$ & & I5.375 (9.| I0-25.95।) & $<0.001$ \\
\hline$\geq 80$ & $40.239(|8.47|-87.660)$ & & $64.438(28.299-146.725)$ & $<0.001$ \\
\hline Sex & & 0.367 & & \\
\hline Female & I [reference] & & - & \\
\hline Male & $1.133(0.864-0.486)$ & & - & \\
\hline Race/ethnicity & & $<0.001$ & & $<0.001$ \\
\hline White & I [reference] & & I [reference] & \\
\hline Black & $2.480(1.833-3.357)$ & & $2.536(1.86 \mathrm{I}-3.456)$ & $<0.001$ \\
\hline Other ethnicity & $0.582(0.323-1.050)$ & & $0.553(0.3 .6-0.998)$ & 0.047 \\
\hline Histology & & 0.408 & & \\
\hline Papillary craniopharyngioma & I [reference] & & - & \\
\hline Adamantinomatous craniopharyngioma & $0.715(0.459-1.114)$ & & - & \\
\hline Craniopharyngioma NOS & $0.650(0.423-0.999)$ & & - & \\
\hline Size & & 0.001 & & $<0.001$ \\
\hline$<30 \mathrm{~mm}$ & I [reference] & & I [reference] & \\
\hline$\geq 30 \mathrm{~mm}$ & $1.082(0.825-1.419)$ & & $1.694(1.278-2.247)$ & \\
\hline Surgery & & 0.92 & & \\
\hline No surgery & I [reference] & & - & \\
\hline STR & $1.044(0.719-1.517)$ & & - & \\
\hline GTR & $1.102(0.765-1.589)$ & & - & \\
\hline Surgery, NOS & $1.372(0.426-4.425)$ & & - & \\
\hline Radiation & & 0.004 & & 0.004 \\
\hline Yes & I [reference] & & I [reference] & \\
\hline No & $1.718(1.213-2.433)$ & & $1.675(1.179-2.38 I)$ & \\
\hline \multicolumn{5}{|l|}{ Year of diagnosis } \\
\hline $2004-2010$ & I [reference] & 0.24 & - & \\
\hline $2010-2017$ & $0.828(0.604-1.134)$ & & - & \\
\hline
\end{tabular}

Abbreviation: NOS, not otherwise specified.

\section{Characteristics of Craniopharyngiomas}

Consistent with most previous studies, our cohort exhibits two peaks of age of onset in CPs seen in childhood (0-19 years) as well as mid-adulthood (40-59 years). Currently, controversies still exist in the risk factor for survival of age at diagnosis. Several researches have reported that compared to adolescent and adult patients, younger patients experience better long-term survival. ${ }^{14,15}$ Meanwhile, some studies insist the opposite opinions that there are better outcomes in older patients with CPs or at least similar survival for all ages. 5,16,17 However, the sample size of all these studies were no more than 250 patients. According to our cohort, the study implicates that as age increases, the overall survival rate decreases, and age $\geq 80$ is the most dangerous factor (HR, 64.438; 95\% CI, 28.299-146.725). It is interesting that the risk factor analyses identified black ethnicity as a risk factor for OS for craniopharyngioma (HR: 2.536; 95\% CI: 1.861-3.456) when compared with white patients. In the previous study of Brad E. Zacharia et al, black patients approximately doubled the odds of decreasing OS (HR: 1.84; CI: 95\%: 1.08-3.15). ${ }^{1}$ Bunin et al reported the probabilities of 


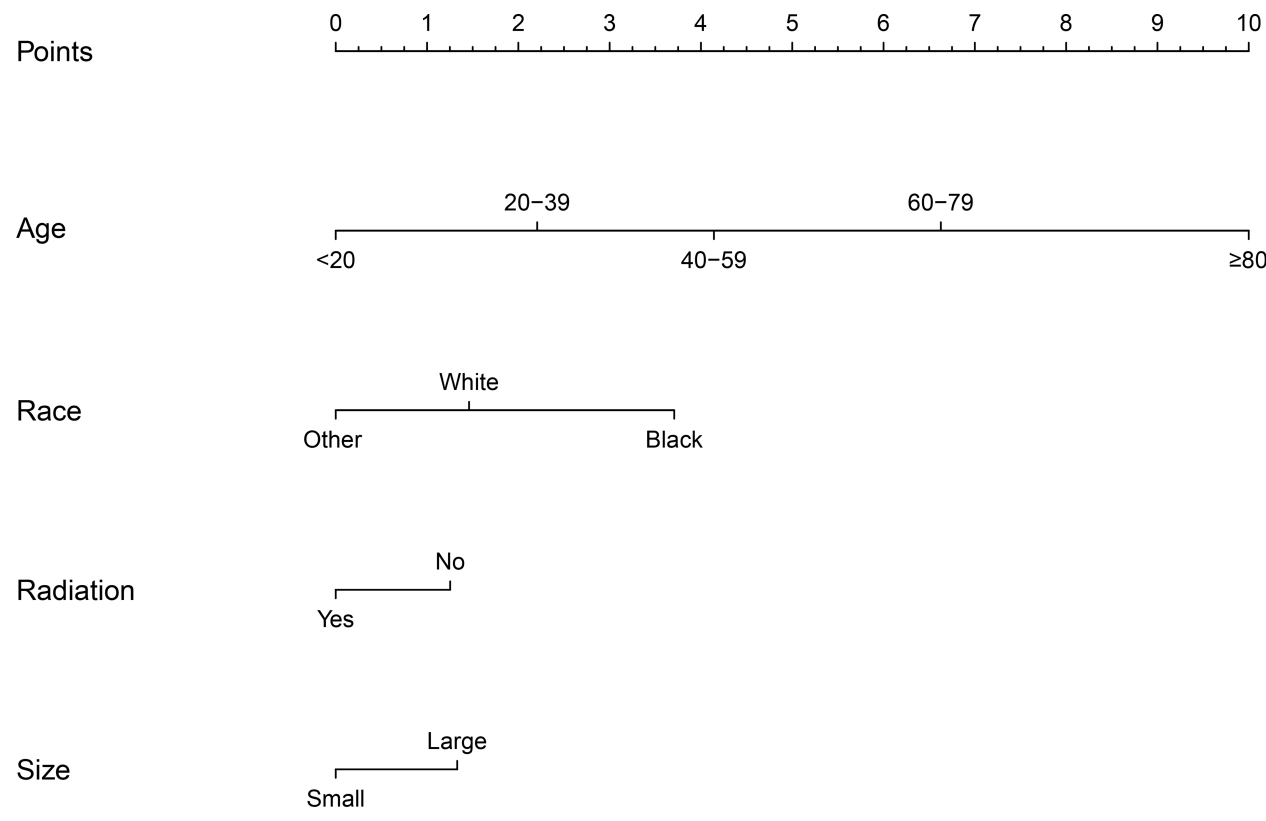

Total Points

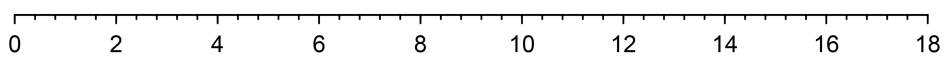

3-year OS

$\begin{array}{llllll}0.95 & 0.9 & 0.8 & 0.7 & 0.6 & 0.50 .40 .3\end{array}$

5-year OS

$\begin{array}{llllll}0.95 & 0.9 & 0.8 & 0.7 & 0.6 & 0.50 .40 .3\end{array}$

10-year OS

$\begin{array}{llllll}0.95 & 0.9 & 0.8 & 0.7 & 0.6 & 0.50 .40 .3\end{array}$

Figure 3 Prediction model nomogram. For each indicator, a vertical line is drawn downward to determine the points, and the points are added together to yield the total points on the bottom, and a vertical line is drawn from that location down to the probability of survival of craniopharyngioma. The figure on this line indicates the predicted 3-, 5- and 10-year of overall survival. The model includes the 4 variables represented in the final prediction nomogram: age, ethnicity, size, radiation.

African American children were more than twice of that in white children. ${ }^{16}$ Our findings are consistent with the results from these studies. In addition, some studies of small size sample have observed higher mortality among female patients. ${ }^{4}$ They explained this finding by an even higher cardiovascular risk rate observing in female patients. ${ }^{18}$ However, Mark Wijnen et al found that despite the statistical significance of hypertension (51\% vs $33 \%$; $\mathrm{P}<0.05)$ and dyslipidemia $(29 \%$ vs $16 \% ; \mathrm{P}<0.05)$ of females, females are also in agreement with males on patient characteristics. ${ }^{17}$ Uniformly, we found no gender differential in the changes of OS rates. No surprise, those with larger tumors (size $\geq 30 \mathrm{~mm}$ ) experienced improved 3-, 5- and 10-year survival rates due to the close anatomical proximity to the optic chiasm, hypothalamus and pituitary gland. Furthermore, our results show that there was no statistical significance among different histology in the multivariable analysis.

Due to convenient obtainment in consulting room of the variables in our nomogram and no ambiguity, doctor more accurately identify patients at different risk of CPs. By comparing the prediction results of nomogram, a patient with a high risk (black ethnicity, for example) should choose more conservative treatment for CPs and be 
A

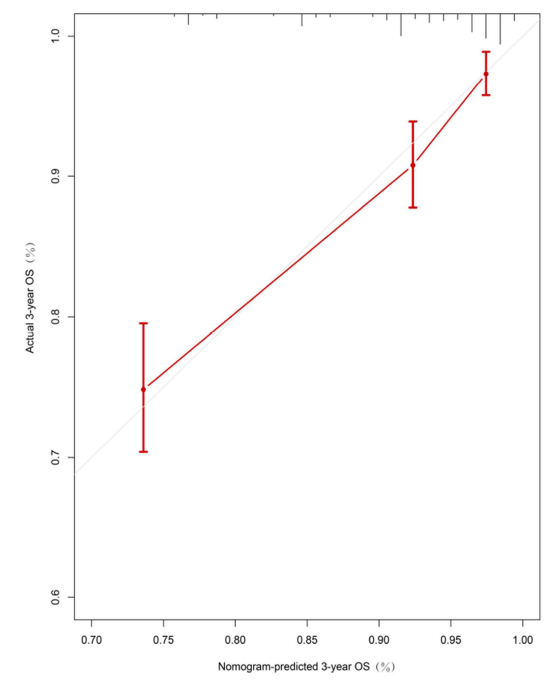

B

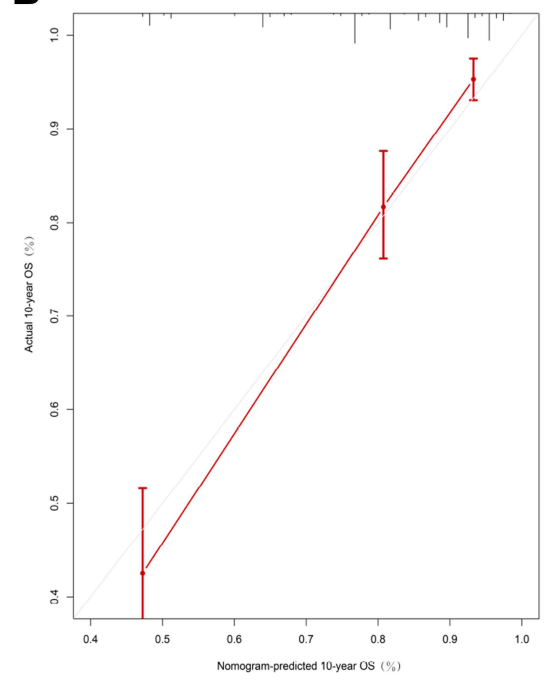

C

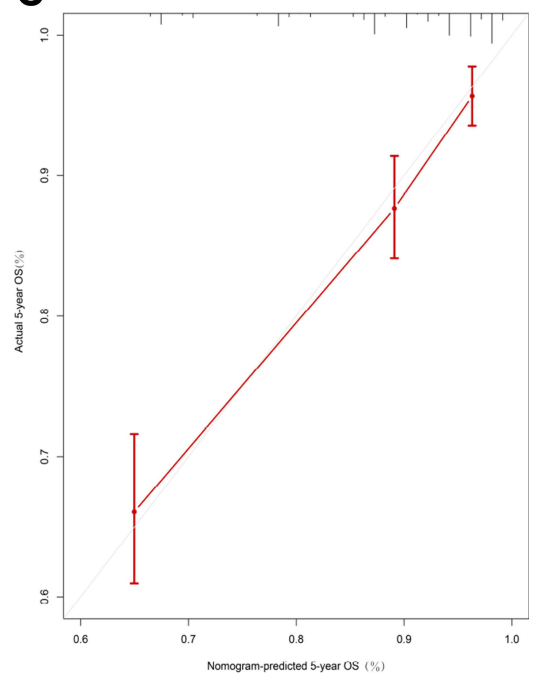

Figure 4 Calibration curve of the nomogram predicting (A) 3-year, (B) 10-year, and (C) 5-year OS patients with CPs.

placed under strict monitoring for symptoms of complication such as endocrine deficiencies, visual acuity, hypothalamic obesity, etc. For such patients, there is a need to further evaluate and weigh the benefits and risks of early treatment intervention.

In addition to the above-mentioned related factors affecting the survival rate of craniopharyngioma, the patients' quality of life (QOL) is also the focus of attention for patients with craniopharyngioma. There are literatures showing that patients undergoing surgery have an impact on memory, but have little impact on intelligence. ${ }^{19-21}$ Some reports suggest that it has no difference on neurocognitive function before and after surgery. ${ }^{22}$ Most children and adults also successfully returned to normal lives. However, there is still a lack of well-documented prospective studies to confirm this result.

\section{Tumor Management}

Craniopharyngiomas are notoriously difficult to treat. Based on previous reports, the mainstream treatment of CPs is still GTR. Neurosurgeons tend to perform greater numbers of GTR (65-90\%) when compared to STR (10$50 \%){ }^{23}$ Yang, I. et al reported the results that STR + RT have a similar outcome compared to GTR. ${ }^{24}$ Many researchers considered GTR as a risk factor associated with recurrence and survival. ${ }^{14,25,26}$ Our research had come to the same conclusion. In the univariable analysis, patients who received GTR had higher HR compared with those who underwent STR with or without radiation therapy. Even more interestingly, GTR were at a higher risk of worsen OS compared with no surgery, although not statistically significant. There are also different methods for surgical removal of craniopharyngiomas. Chakrabarti et al believe that cystic craniopharyngiomas on the sella are more suitable for transsphenoidal surgery, while tumors with calcification or solid tumors are more suitable for transcranial surgery. ${ }^{27}$ Consequently, our study did not integrate surgical approach into their models and this needs further research. Furthermore, the treatment of surgical resection not only affect the survival rate, but also affect the endocrine results. Before surgery, patients will have varying degrees of hypogonadism and $\mathrm{GH}$ deficiency. ${ }^{28}$ New endocrine dysfunction will also appear in patients undergoing surgery. Diabetes insipidus is the common complication of transsphenoidal and transcranial surgery. ${ }^{19,27}$ It is difficult to recover from the preoperative endocrine function defects after craniopharyngioma surgery, ${ }^{19}$ so it is especially important to avoid new dysfunctions. Given the heterogeneity of population, this nomogram needs further prudent verification in other centers before extrapolation. Hill, T. K. et al reported that radiation with limited or no surgery is similar to control rates of GTR, with a $>90 \% 10$-year overall Survival. ${ }^{29}$ Michael S. Rutenberg et al found that the 3-year local control and overall survival rates of 14 adult patients were both $100 \%{ }^{30}$ According to Clark AJ et al's earlier reports, STR+XRT was similar OS rate as GTR in terms of pediatric craniopharyngioma treatment. ${ }^{31}$ Radiotherapy is 


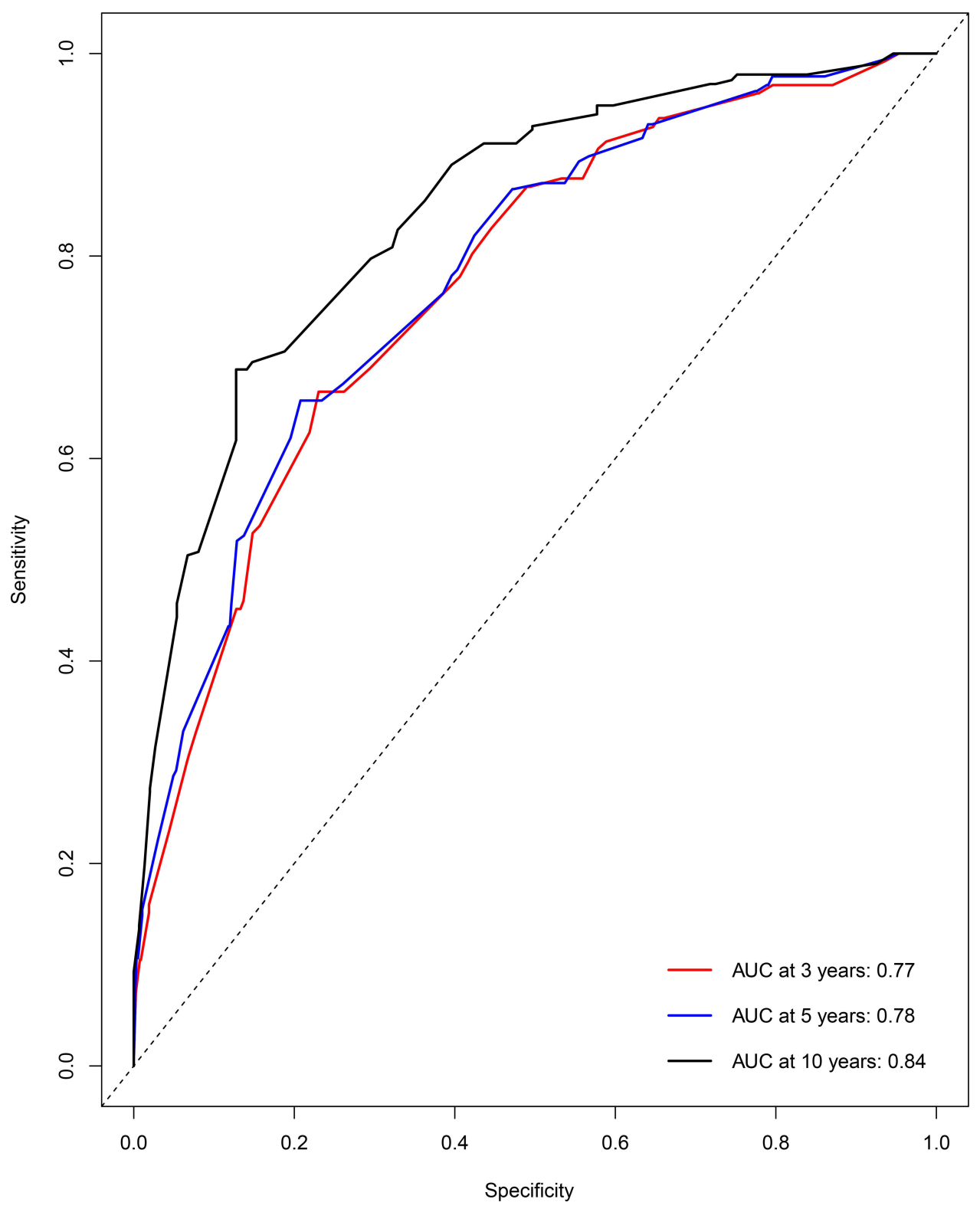

Figure 5 ROC curve of the nomogram predicting 3-year, 5-year, and 10-year OS patients with CPs.

a significant prognostic factor in both multivariate analysis and the nomogram model correlated with OS in our study. In our study, we also found that STR+XRT was better OS rate than GTR in Figure $4 \mathrm{H}$. This may be due to the difficulty of GTR leading to postoperative complications. However, it also shows that STR+RT is one of the options for patients with craniopharyngioma who are at greater risk. For different methods of radiotherapy, internal irradiation is more suitable for patients with purely cystic craniopharyngioma, while external radiation and stereotactic radiosurgery are indicated in patients with recurrent craniopharyngiomas or STR. ${ }^{32,33}$ Radiotherapy is a crucial factor impacting patient prognosis and survival.
Although radiotherapy may be beneficial for the survival long-term prognosis in most retrospective studies, the role of RT in the different characteristics' patients of craniopharyngioma remains to be undefined, and further prospective research will be demanded.

\section{Limitation}

The major strength of this study lies in its large size sample and the longer follow-up duration. We comprehensively analyzed various risk factors associated with craniopharyngiomas, the nomogram prediction model was induced successfully with high prediction accuracy. However, the research still has some limitations that the database lacks detailed prognosis 
and drug treatment, which are some intrinsic to the SEER. First, the major drawback of our study is that we failed to collect some potentially related variables into the nomogram, like complications, laboratory indicators, recurrence data, type of radiotherapy and surgery. Second, when taking up the analysis of age, we found advanced age ( $\geq 80$ years) can potentially be affected by other diseases and further in-depth research is required. Unfortunately, numbers of reported cases of this age group in the SEER database were very low $(0.8 \%)$. Third, with advancement in the technologies for surgical and endocrinological management in $\mathrm{CP}$, it may impact on survival. Such detailed data are required to optimize analysis. In addition, the current analysis was retrospective, some hidden selection bias may exist. In the future, it is necessary to use prospective randomized prospective studies or use other databases to support and verify this hypothesis.

\section{Conclusion}

In conclusion, this study found that age, ethnicity, tumor size and radiation are the independent risk factors for OS of craniopharyngiomas. A nomogram model of 3-, 5- and 10 -year OS among patients with craniopharyngiomas was constructed based on clinical data. The doctors can predict patient outcomes to some degree during initial visits, when the condition of the patients is not clear and complete. Simultaneously, our finding also has verified some independent factors influencing the OS of CPs.

\section{Acknowledgments}

Haibo Teng and Ouying Yan are co-first authors. We thank all patients and the Surveillance, Epidemiology, and End Results program for the use of the cancer registry data.

\section{Disclosure}

The authors report no conflicts of interest in this work.

\section{References}

1. Zacharia BE, Bruce SS, Goldstein H, Malone HR, Neugut AI, Bruce JN. Incidence, treatment and survival of patients with craniopharyngioma in the surveillance, epidemiology and end results program. Neuro Oncol. 2012;14(8):1070-1078. doi:10.1093/neuonc/nos142

2. Muller HL, Merchant TE, Warmuth-Metz M, Martinez-Barbera JP, Puget S. Craniopharyngioma. Nat Rev Dis Primers. 2019;5(1):75.

3. Müller H, Merchant TE, Puget S, Martinez-Barbera JPJNRE. New outlook on the diagnosis, treatment and follow-up of childhood-onset craniopharyngioma. Nat Rev Endocrinol. 2017;13(5):299-312. doi:10.1038/nrendo.2016.217

4. Pereira AM, Schmid EM, Schutte PJ, et al. High prevalence of long-term cardiovascular, neurological and psychosocial morbidity after treatment for craniopharyngioma. Clin Endocrinol. 2005;62 (2): 197-204.
5. Karavitaki N, Brufani C, Warner JT. Craniopharyngiomas in children and adults: systematic analysis of 121 cases with long-term follow-up. Clin Endocrinol. 2005;62(4):397-409.

6. Jane JA, Laws ER. Craniopharyngioma. Pituitary. 2006;9 (4):323-326. doi:10.1007/s11102-006-0413-8

7. Hoffman HJ, Silva M, Humphreys RP, Drake JM, Smith ML, Blaser S. Aggressive surgical management of craniopharyngiomas in children. Journal of Neurosurgery. 1992;76(1):47-52.

8. Yasargil MG, Curcic M, Kis M, Siegenthaler G, Teddy PJ, Roth P. Total removal of craniopharyngiomas. Approaches and long-term results in 144 patients. Journal of Neurosurgery. 1990;73(1):3-11. doi: $10.3171 /$ jns. 1990.73 .1 .0003

9. Devile CJ, Grant DB, Hayward RD, Stanhope R. Growth and endocrine sequelae of craniopharyngioma. Archives of Disease in Childhood. 1996;75(2):108-114. doi:10.1136/adc.75.2.108

10. Müller H, Gebhardt U, Faldum A, et al. Functional capacity and body mass index in patients with sellar masses - cross-sectional study on 403 patients diagnosed during childhood and adolescence. Child's Nervous System: ChNS: Official Journal of the International Society for Pediatric Neurosurgery. 2005;21(7):539-545. doi:10.1007/s00381-005-1166-9

11. Lo AC, Howard AF, Nichol A, et al. Long-term outcomes and complications in patients with craniopharyngioma: the British Columbia Cancer Agency experience. Int J Radiat Oncol Biol Phys. 2014;88(5):1011-1018. doi:10.1016/j.ijrobp.2014.01.019

12. Warren JL, Klabunde CN, Schrag D. Overview of the SEER-Medicare data: content, research applications, and generalizability to the United States elderly population, Med Care. 2002;40: IV-3-18

13. Lee EJ, Cho YH, Hong SH, Kim JH, Kim CJ. Is the complete resection of craniopharyngiomas in adults feasible considering both the oncologic and functional outcomes? J Korean Neurosurg Soc. 2015;58(5):432-441. doi:10.3340/jkns.2015.58.5.432

14. Fahlbusch R, Honegger J, Paulus W. Surgical treatment of craniopharyngiomas: experience with 168 patients. J Neurosurgery. 1999;90(2):237-250.

15. Bülow B, Attewell R, Hagmar L, Malmström P, Nordström CH, Erfurth EM. Postoperative prognosis in craniopharyngioma with respect to cardiovascular mortality, survival, and tumor recurrence. The Journal of Clinical Endocrinology and Metabolism. 1998;83 (11):3897-3904. doi:10.1210/jcem.83.11.5240

16. Bunin GR, Surawicz TS, Witman PA. The descriptive epidemiology of craniopharyngioma. J Neurosurgery. 1997;3(6):e1.

17. Wijnen M, Olsson DS, van den Heuvel-eibrink MM, et al. Excess morbidity and mortality in patients with craniopharyngioma: a hospital-based retrospective cohort study. Eur $J$ Endocrinol. 2018;178(1):93-102. doi:10.1530/EJE-17-0707

18. Erfurth EM, Holmer H, Fjalldal SB. Mortality and morbidity in adult craniopharyngioma. Pituitary. 2013;16(1):46-55. doi:10.1007/ s11102-012-0428-2

19. Di Rocco C, Caldarelli M, Tamburrini G, Massimi L. Surgical management of craniopharyngiomas--experience with a pediatric series. Journal of Pediatric Endocrinology \& Metabolism: JPEM. 2006;19 Suppl 1:355-366.

20. Hoffman H, De Silva M, Humphreys R, Drake J, Smith M, Blaser SI. Aggressive surgical management of craniopharyngiomas in children. Journal of Neurosurgery. 1992;76(1):47-52. doi:10.3171/ jns.1992.76.1.0047

21. Carpentieri S, Waber D, Scott R, et al. Memory deficits among children with craniopharyngiomas. Neurosurgery. 2001;49 (5):1053-1057. doi:10.1097/00006123-200111000-00005

22. Honegger J, Barocka A, Sadri B, Fahlbusch R. Neuropsychological results of craniopharyngioma surgery in adults: a prospective study. Surgical Neurology. 1998;50(1):19-28. doi:10.1016/s0090-3019(97) 00507-7 
23. Muller HL. Paediatrics: surgical strategy and quality of life in craniopharyngioma. Nat Rev Endocrinol. 2013;9(8):447-449. doi:10.1038/nrendo.2013.125

24. Yang I, Sughrue ME, Rutkowski MJ, et al. Craniopharyngioma: a comparison of tumor control with various treatment strategies. Neurosurg Focus. 2010;28(4):E5. doi:10.3171/2010.1.FOCUS09307

25. Sanford RA. Craniopharyngioma: results of survey of the American Society of Pediatric Neurosurgery. Pediatric Neurosurgery. 1994;21:39-43.

26. Tomita T, McLone DG. Radical resections of childhood craniopharyngiomas. Pediatric Neurosurgery. 1993;19(1):6-14.

27. Chakrabarti I, Amar A, Couldwell W, Weiss MH. Long-term neurological, visual, and endocrine outcomes following transnasal resection of craniopharyngioma. Journal of Neurosurgery. 2005;102 (4):650-657. doi:10.3171/jns.2005.102.4.0650

28. Karavitaki N, Brufani C, Warner J, et al. Craniopharyngiomas in children and adults: systematic analysis of 121 cases with long-term follow-up. Clinical Endocrinology. 2005;62(4):397-409. doi:10.1111/j.1365-2265.2005.02231.x
29. Hill TK, Baine MJ, Verma V. Patterns of care in pediatric craniopharyngioma: outcomes following definitive radiotherapy. Anticancer Res. 2019;39(2):803-807.

30. Rutenberg MS, Rotondo RL, Rao D, et al. Clinical outcomes following proton therapy for adult craniopharyngioma: a single-institution cohort study. J Neurooncol. 2020;147(2):387-395. doi:10.1007/ s11060-020-03432-9

31. Clark AJ, Cage TA, Aranda D, et al. A systematic review of the results of surgery and radiotherapy on tumor control for pediatric craniopharyngioma. Childs Nerv Syst. 2013;29(2):231-238. doi:10.1007/s00381-012-1926-2

32. Honegger J, Tatagiba M. Craniopharyngioma surgery. Pituitary. 2008;11(4):361-373. doi:10.1007/s11102-008-0137-z

33. Chiou S, Lunsford L, Niranjan A, Kondziolka D, Flickinger JJN. Stereotactic radiosurgery of residual or recurrent craniopharyngioma, after surgery, with or without radiation therapy. Neuro-Oncology. 2001;3(3):159-166. doi:10.1093/neuonc/3.3.159
International Journal of General Medicine

\section{Publish your work in this journal}

The International Journal of General Medicine is an international, peer-reviewed open-access journal that focuses on general and internal medicine, pathogenesis, epidemiology, diagnosis, monitoring and treatment protocols. The journal is characterized by the rapid reporting of reviews, original research and clinical studies
Dovepress

across all disease areas. The manuscript management system is completely online and includes a very quick and fair peer-review system, which is all easy to use. Visit http://www.dovepress.com/ testimonials.php to read real quotes from published authors. 